\title{
Bioactivity Guided Fractionation of Ethanol Extract of Caesalpinia digyna Rottler Roots
}

\author{
Jitender Singh, Ashwani Kumar*, Anupam Sharma \\ Department of Pharmacognosy, University Institute of Pharmaceutical Sciences, Panjab University, Chandigarh-160014, INDIA.
}

\begin{abstract}
Background: Authors have reported earlier that ethanol extract of Caesalpinia digyna Rottler roots exhibits significant antianxiety activity at $400 \mathrm{mg} / \mathrm{kg}$, po, in mice using elevated plus-maze (EPM). Objective: Aim of the study was to isolate antianxiety principle(s) from ethanol extract of $C$. digyna roots following bioactivity guided fractionation approach. Materials and Methods: Bioactive ethanol extract was partitioned with ethyl acetate to get ethyl acetate soluble (EASF) and ethyl acetate insoluble (EAIF) fractions. A compound $\left(C D_{1}\right)$ precipitated from EASF. The two fractions and $C D_{1}$ were evaluated for antianxiety activity in mice. Column chromatography of EASF yielded 5 fractions $\left(F_{1}-F_{5}\right)$, all of which were evaluated for antianxiety activity using EPM. Results: Present study revealed that EASF ( $80 \mathrm{mg} / \mathrm{kg})$ and $C D_{1}(40 \mathrm{mg} / \mathrm{kg})$ exhibited significant antianxiety activity, while EAIF does not. Among the five fractions, only $F_{4}(40 \mathrm{mg} / \mathrm{kg}$, po), exhibited significant antianxiety activity, which was statistically comparable to that of diazepam (2 mg/ $/ \mathrm{kg}$ ). Conclusion: Present investigation reveals that EASF obtained by partitioning of ethanol extract of $C$. digyna roots with
\end{abstract}

ethyl acetate, and a compound $\mathrm{CD}_{1}$, isolated from EASF, exhibit significant antianxiety activity. Among 5 fractions $\left(F_{1}-F_{5}\right)$ obtained from column chromatography of EASF, only $F_{4}$ exhibited significant antianxiety activity. $F_{4}$ is being processed further to isolate the anxiolytic constituent(s), and $\mathrm{CD}_{1}$ is being characterized.

Key words: Antianxiety, Bioactivity-guided fractionation, Caesalpinia digyna, Elevated plus-maze.

Correspondence:

Dr Ashwani Kumar, Department of Pharmacognosy,

University Institute of Pharmaceutical Sciences, Panjab University,

Chandigarh-160014, INDIA.

Phone no: +918437843949

E-mail: bashwani@pu.ac.in

DOI: 10.5530/pj.2016.2.11

\section{INTRODUCTION}

Caesalpinia digyna Rottler (Caesalpiniaceae) is a large, perennial, prickly shrub or climber. It is commonly known as Teri Pods (English), Vakerimul (Hindi) or Udakiryaka (Sanskrit). Roots of this plant have been used traditionally as astringent, febrifuge and nervine tonic. The roots have marked astringent and antipyretic properties. In some parts of Burma, root powder mixed with water, is drunk as a febrifuge and is said to have soothing effects on nerves. C. digyna is one of the ingredients of an indigenous drug preparation Geriforte, which has been used for curing senile pruritis. ${ }^{1-2}$ The formulation has also been reported to exhibit antifatigue and anti-stress effect. ${ }^{3}$ Methanol root extract of the plant has been reported to have antioxidant, antidiabetic and radioprotective effect. ${ }^{4-6}$ Bergenin, isolated from the roots of $C$. digyna has been reported to exhibit Type 2 antidiabetic activity. ${ }^{7-8}$ Earlier studies by the authors have reported that ethanol extract of $C$. digyna roots shows significant antianxiety activity at $400 \mathrm{mg} / \mathrm{kg}$, po, in mice using elevated plus-maze. ${ }^{9}$ Continuing with the investigation on the ethanol extract of the plant, a fraction and a pure compound with significant antianxiety activity have been isolated. Authors intend to share these findings through this communication.

\section{MATERIALS AND METHODS}

\section{Plant material}

Dried roots of C. digyna were purchased from Manilal Lallubhai \& Co., Mumbai, India. Identity of the plant drug was confirmed through the Head, Raw Materials, Herbarium \& Museum at National Institute of Science Communication and Information Resources (NISCAIR), New Delhi, India, vide letter number NISCAIR/RHMD/ Consult/2013/2351-131-3, dated 19.12.2013.

\section{Preparation of extracts}

C. digyna roots $(1 \mathrm{~kg})$ were packed in a Soxhlet apparatus fitted over $5 \mathrm{~L}$ round-bottom flask. The drug was successively extracted with petroleum ether, chloroform and ethanol ( $3 \mathrm{~L}$ each) for $15 \mathrm{~h}$ over boiling water bath. Solvents were recovered using rotary vacuum evaporator (EYELA N1100).

\section{Animals}

Laca mice (20-30 g) of either sex, procured from the Animal House, Panjab University, Chandigarh, were maintained in a $12 \mathrm{~h}$ light/dark cycle at a temperature of $25 \pm 2^{\circ} \mathrm{C}$. The mice were fed standard pellet diet (Ashirwad Industries, Mohali) and water. Food was withdrawn $4 \mathrm{~h}$ before the experiment though water was allowed ad libitum. Six mice each were allocated to different experimental groups. All the studies were performed as per the guidelines of the Institutional Ethical Committee of Panjab University, Chandigarh (Approval No. IAEC/411, dated 11.09. 2013).

\section{Preparation of dose}

Carboxy methyl cellulose $(0.5 \% \mathrm{w} / \mathrm{v}$ aqueous $)$ containing $5 \%$ tween 80 was used as vehicle for preparing the suspension of test samples and diazepam (standard anxiolytic). The vehicle alone served as control. Test material and diazepam (Jawa Pharmaceuticals Pvt. Ltd., Gurgaon) were suspended in the vehicle in such concentrations as to administer appropriate doses of these to mice in a volume ranging from 0.20 to $0.30 \mathrm{ml}$, po, using a tuberculin syringe fitted with an oral canula.

\section{Bioactivity-guided fractionation}

Dried ethanol extract (105 g) was suspended uniformly in $150 \mathrm{ml}$ water, placed in three-necked round bottom flask fitted with Teflon stirrer, and partitioned with ethyl acetate $(100 \mathrm{ml})$ by heating $\left(50^{\circ} \mathrm{C}\right)$ for $30 \mathrm{~min}$ 


\begin{tabular}{cccc} 
Table 1: Antianxiety activity profile of fractions of ethanol extract of C. digyna roots and CD, using EPM \\
\hline Treatment & Dose $(\mathbf{m g} / \mathbf{k g})$ & $\begin{array}{c}\text { mean* number of } \\
\text { entries in open arm }\end{array}$ & $\begin{array}{c}\text { mean* time spent in } \\
\text { open arm (sec) }\end{array}$ \\
\hline Control (Vehicle) & - & $2.2 \pm 0.30^{\mathrm{b}}$ & $2.7 \pm 0.39^{\mathrm{b}}$ \\
Diazepam & 2 & $7.2 \pm 0.60^{\mathrm{a}}$ & $14.2 \pm 1.14^{\mathrm{a}}$ \\
EASF & 80 & $3.3 \pm 0.76^{\mathrm{b}}$ & $7.4 \pm 0.52^{\mathrm{a}, \mathrm{b}}$ \\
EAIF & 275 & $2.3 \pm 0.33^{\mathrm{b}}$ & $2.9 \pm 0.67^{\mathrm{b}}$ \\
$\mathrm{CD}_{1}$ & 40 & $5.5 \pm 0.76^{\mathrm{a}}$ & $8.3 \pm 0.92^{\mathrm{a}, \mathrm{b}}$ \\
\hline
\end{tabular}

$\overline{{ }^{*} \mathrm{n}=6 \text {, mean } \pm \text { SEM. }{ }^{\mathrm{a}} \mathrm{p}<0.05 \text { vs. control; }{ }^{\mathrm{b}} \mathrm{p}<0.05 \text { vs. diazepam; one way ANOVA followed by Tukey's multiple range }}$ test.

Table 2: Antiaxiety activity profile of fractions, obtained after column chromatography of EASF, using EPM

\begin{tabular}{cccc}
\hline Treatment & Dose $(\mathrm{mg} / \mathrm{kg})$ & $\begin{array}{c}\text { Mean* number of } \\
\text { entries in open arm }\end{array}$ & $\begin{array}{c}\text { Mean* time spent in } \\
\text { open arm }(\mathrm{sec})\end{array}$ \\
\hline Control (Vehicle) & - & $2.2 \pm 0.31^{\mathrm{b}}$ & $2.7 \pm 0.39^{\mathrm{b}}$ \\
Diazepam & 2 & $7.2 \pm 0.60^{\mathrm{a}}$ & $14.2 \pm 1.14^{\mathrm{a}}$ \\
$\mathrm{F}_{1}$ & 2 & $2.2 \pm 0.31^{\mathrm{b}}$ & $3.2 \pm 0.58^{\mathrm{b}}$ \\
$\mathrm{F}_{2}$ & 3 & $2.0 \pm 0.36^{\mathrm{b}}$ & $2.8 \pm 0.68^{\mathrm{b}}$ \\
$\mathrm{F}_{3}$ & 4 & $2.7 \pm 0.33^{\mathrm{b}}$ & $3.1 \pm 0.58^{\mathrm{b}}$ \\
$\mathrm{F}_{4}$ & 40 & $4.5 \pm 0.62^{\mathrm{a}} \mathrm{b}$ & $6.2 \pm 0.81^{\mathrm{a}, \mathrm{b}}$ \\
$\mathrm{F}_{5}$ & 30 & $2.2 \pm 0.31^{\mathrm{b}}$ & $2.9 \pm 0.65^{\mathrm{b}}$ \\
\hline${ }^{*} \mathrm{n}=6$, mean \pm SEM. ${ }^{\mathrm{a}} \mathrm{p}<0.05$ vs. control; ${ }^{\mathrm{b}} \mathrm{p}<0.05$ vs. diazepam; one way ANOVA followed by
\end{tabular}

Tukey's multiple range test.

with continuous stirring. The procedure was repeated five times. All the ethyl acetate fractions were pooled. Solvents from the pooled fractions and the remaining aqueous fraction were recovered under reduced pressure using rotary vacuum evaporator to get ethyl acetate soluble fraction (EASF) and ethyl acetate insoluble fraction (EAIF) respectively.

A solid brown material precipitated from the concentrated EASF, was separated, washed $(\times 3)$ with ethanol and recrystallized using methanol to get a crystalline compound $\mathrm{CD}_{1}$. Antianxiety activity of EASF, EAIF and $C_{1}$ was evaluated at 80,275 and $40 \mathrm{mg} / \mathrm{kg}$, po, respectively.

EASF (33 g) was subjected to column chromatography using silica gel (\#60-120, s.d. fine-Chem Ltd, Mumbai; 900 g). Elution was done with pet ether, chloroform and methanol, in appropriate proportions. A total of 158 fractions, each of $500 \mathrm{ml}$, were collected and pooled on the basis of TLC profile to get five fractions - $\mathrm{F}_{1}-\mathrm{F}_{5}$. These were subjected to antianxiety activity evaluation at 2, 3, 4, 40 and $30 \mathrm{mg} / \mathrm{kg}$, po, respectively.

\section{Antianxiety activity}

Antianxiety activity was evaluated using the modified elevated plusmaze (EPM). ${ }^{10-11}$ The apparatus comprising two open arms $(16 \times 5 \mathrm{~cm})$ and two closed arms $(16 \times 5 \times 12 \mathrm{~cm})$ having an open roof, was kept elevated $(25 \mathrm{~cm})$ from the floor for evaluating antianxiety behavior in animals. During the entire experiment, mice were allowed to socialize. Every precaution was taken to ensure that no external stimuli, other than the height of the plus-maze, could invoke anxiety in mice. Doses were administered orally using tuberculin syringe fitted with an oral canula. The dose administration schedule was so adjusted that each mouse was having its turn on the EPM 60 min after the administration of vehicle, diazepam or the test material. Each mouse was placed at the center of EPM with its head facing towards the open arm. During 5 min duration of the experiment, behavior of the mouse was recorded as (a) the number of entries into the open arms and (b) mean time spent by the mouse in open arms.

\section{Statistical analysis}

The data have been expressed as mean \pm standard error of mean (SEM). Significant differences among the groups were assessed using one way analysis of variance (ANOVA) using GraphPad Prism 5. The test was followed by Tukey's multiple range test; $\mathrm{p}$ values less than 0.05 were considered as significant.

\section{RESULTS AND DISCUSSION}

Previous studies by the authors have reported that among the four extracts namely, petroleum ether, chloroform, ethanol and water of C. digyna roots, only ethanol extract exhibits significant antianxiety activity in mice at $400 \mathrm{mg} / \mathrm{kg}$, po., using EPM. ${ }^{9}$ In the present investigations, doses of the test materials were selected taking into account their yield. It was planned to subject bioactive ethanol extract of the plant to bioactivity guided fractionation with a view to isolate antianxiety fraction(s) or compound(s). Thus, the ethanol extract was partitioned with ethyl acetate to get EASF $(19.8 \% \mathrm{w} / \mathrm{w})$, EAIF $(69.0 \%$ $\mathrm{w} / \mathrm{w})$ and $\mathrm{CD}_{1}(10.8 \% \mathrm{w} / \mathrm{w})$. Results of antianxiety activity evaluation of EASF, EAIF and $\mathrm{CD}_{1}$ are shown in Table 1. EASF and $\mathrm{CD}_{1}$ exhibited significant antianxiety activity at a dose of 80 and $40 \mathrm{mg} / \mathrm{kg}$, po, respectively. However, EAIF did not show any antianxiety effect on mice.

EASF was further subjected to column chromatography. A total of 158 fractions, each of $500 \mathrm{ml}$, were collected during column chromatography of EASF. These were pooled on the basis of similar TLC patterns to get five fractions $-\mathrm{F}_{1}(1.7 \%), \mathrm{F}_{2}(4.1 \%), \mathrm{F}_{3}(4.9 \%), \mathrm{F}_{4}(49.0 \%)$ and $\mathrm{F}_{5}(36.1 \%)$. All the five fractions were evaluated for antianxiety activity at 2, 3, 4, 40 and $30 \mathrm{mg} / \mathrm{kg}$, po (Table 2). Fraction $\mathrm{F}_{4}$ exhibited significant antianxiety activity at $40 \mathrm{mg} / \mathrm{kg}$, po, using EPM. $\mathrm{F}_{4}$, eluted using chloroform-methanol (98:2), showed one major and five minor spots on TLC (mobile phase: toluene-ethyl acetate, 7.5:2.5). $\mathrm{F}_{4}$ shall be subjected to column chromatography, and $\mathrm{CD}_{1}$ is in the process of being characterized.

\section{CONCLUSION}

Present investigation reveals that ethyl acetate soluble fraction obtained by partitioning of ethanol extract of Caesalpinia digyna roots with ethyl acetate, and a compound $\mathrm{CD}_{1}$, isolated from ethyl acetate soluble fraction, exhibit significant antianxiety activity. Out of five fractions 
$\left(\mathrm{F}_{1}-\mathrm{F}_{5}\right)$ obtained by column chromatography of EASF, only $\mathrm{F}_{4}$ exhibits significant antianxiety activity.

\section{ACKNOWLEDGEMENT}

This work has been supported by the University Grants Commission, New Delhi under Grant F.5-94/2007(BSR).

\section{CONFLICT OF INTEREST}

The authors declare no conflicts of interest.

\section{ABBREVIATION USED}

EASF: Ethyl acetate soluble fraction; EAIF: Ethyl acetate insoluble fraction; EPM: Elevated plus-maze.

\section{REFERENCES}

1. Chopra RN, Nayar SL, Chopra IC. Glossary of Indian medicinal plants. New Delhi, India: Council of Scientific and Industrial Research. 1956.p.44.

2. Kiritikar KR, Basu BD. Indian medicinal plants. Dehradun, India: International Booksellers and Publishers. 1984.p.851.
3. Singh N, Nath R, Mishra N, Kohli RP. An experimental evaluation of anti-stress effects of geriforte (an ayurvedic drug). Q J Crude Drug Res.1978;16(3):125.

4. Srinivasan R, Chandrasekar MJN, Nanjan MJ, Suresh B. Antioxidant activity of Caesalpinia digyna root. J Ethnopharmacol. 2007;113(2):284-91.

5. Chandiran S, Vrushabendra SBM, Kumar BP, Narayanan V, Kumar SV,

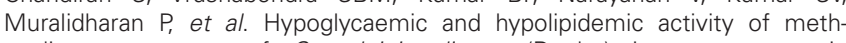
anolic root extract of Caesalpinia digyna (Rottler) in streptozotocin induced diabetic rats. Pharmacologyonline. 2008;2(1):781-9.

6. Singh U, Kunwar A, Srinivasan R, Nanjan MJ, Priyadarsini KI. Differential free radical scavenging activity and radioprotection of Caesalpinia digyna extracts and its active constituent. J Radiat Res. 2009;50(5):425-33.

7. Chaudhry GR, Sharma VN, Dhar ML. Chemical examination of the roots of Caesalpinia digyna. J Sci Ind Res. 1954;13B(3):147-8.

8. Kumar R, Patel DK, Prasad SK, Laloo D, Krishnamurthy S, Hemalatha S. Type 2 antidiabetic activity of bergenin from the roots of Caesalpinia digyna Rottler. Fitoterapia. 2012;83(2):395-401.

9. Kumar A, Singh J, Sharma A. Comparative antianxiety activity evaluation of Argyreia speciosa Linn. (roots), Caesalpinia digyna Rottler (roots) and Sphaeranthus indicus Linn. (flowers). IJPSR. 2015;6(10):4226-9.

10. Pellow S, Chopin P, File SE, Briley M. Validation of open: closed arm entries in an elevated plus-maze as a measure of anxiety in the rats. J Neurosci Methods. 1985; 14(3):149-67.

11. Lister RG. Ethologically based animal models of anxiety disorders. Pharmacol Ther. 1990;46(3):321-40

\section{PICTORIAL ABSTRACT}

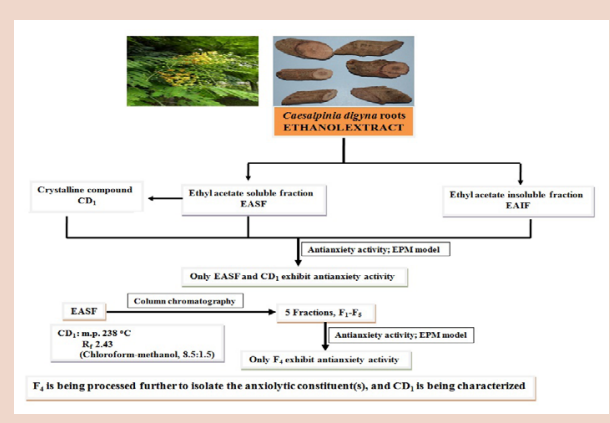

\section{SUMMARY}

- Bioactive ethanol extract of Caesalpinia digyna Rottler roots was subjected to antianxiety activity guided fractionation.

- A crystalline compound $\left(\mathrm{CD}_{1}\right)$ precipitated from ethyl acetate soluble fraction (EASF) obtained from the ethanol extract.

- A fraction $\mathrm{F}_{4}$ obtained from column chromatography of EASF, and $C D$, exhibit significant antianxiety activity in mice at $40 \mathrm{mg} / \mathrm{kg}$, po, which is statistically comparable to that of diazepam $(2 \mathrm{mg} / \mathrm{kg}, \mathrm{po})$

- $\mathrm{F}_{4}$ is being processed further to isolate the anxiolytic constituent(s), and $\mathrm{CD}_{1}$ is being characterized.

\section{ABOUT AUTHORS}

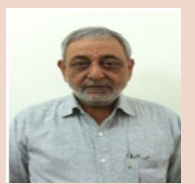

Anupam Sharma: Is Professor of Pharmacognosy at University Institute of Pharmaceutical Sciences, Panjab University, Chandigarh. Professor Sharma has more than 30 years of teaching and research experience. He has guided $10 \mathrm{Ph} . \mathrm{D}$. and $17 \mathrm{M}$ Pharm students. He has 74 national and international publications. His major research areas include "Investigating plant drugs with a view to isolate bioactive constituents; characterization of phytoconstituents; developing standardization parameters for plant drugs".

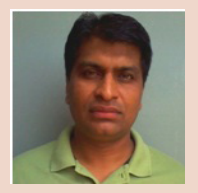

Dr Ashwani Kumar: Is working as Assistant Professor in Pharmacognosy at University Institute of Pharmaceutical Sciences, Panjab University, Chandigarh. His research interests include: a) Development and validation of analytical method for estimation of analytical markers in medicinal plants \& formulations. b) Bioactivity directed fractionation and isolation of natural substances. c) Chemical/biological standardization of herbal drugs. d) Development of evidence-based herbal products. e) Stability testing of Pharmaceutical raw material, intermediates and finished products. 